\title{
Attitudes Toward Dysfunctional Audit Behavior: The Effects Of Locus Of Control, Organizational Commitment, and Position
}

David P. Donnelly, Ph.D., CPA, (Email: dvdon@ksu.edu), Kansas State University

Jeffrey J. Quirin, Ph.D., CMA, (Email: jeffrey.quirin@wichita.edu), Wichita State University

David O'Bryan, Ph.D., CPA, CMA, CFM, CFE, (Email: obryan@pittstate.edu), Pittsburg State University

\begin{abstract}
Dysfunctional audit behavior (DAB) is associated with decreased audit quality (Public Oversight Board 2000). While recent studies suggest that dysfunctional audit behavior is a widespread problem (Smith 1995; Otley and Pierce 1995), extant research fails to adequately explain the causes or determinants of this form of deviant behavior. This study develops and tests a theoretical model that identifies locus of control, position, and organizational commitment as antecedents of attitudes toward DAB. Using a cross-organizational design and a path analysis technique, survey results from 113 auditors support the theoretical model.
\end{abstract}

\section{Introduction}

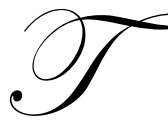

he Panel on Audit Effectiveness was established by the AICPA's Public Oversight Board to examine the issue of audit quality. The Panel gathered information from peer reviews and surveys of financial executives, internal auditors, and external auditing professionals. Their findings indicate that dysfunctional audit behavior (DAB) is a continuing concern for the auditing profession.

The Panel's Report (Public Oversight Board 2000) suggests that time pressures associated with audit budgets, client-imposed and internal deadlines, and unexpected staff turnover are placing significant pressures on audit engagement teams. These pressures can result in reduced audit quality, especially in situations where individual performance is measured primarily by meeting time deadlines and budget estimates. A survey of Big Six audit seniors confirms these concerns. Eighty-nine percent of the respondents admitted to engaging in some form of audit quality reduction behavior (e.g., premature sign-off) and estimated that time underreported was equal to approximately 12.2 percent of hours accurately recorded (Otley and Pierce 1995).

Based on their findings, the Panel recommended that managing the potential risks from excessive time pressures on audit teams must be a high priority for audit firms. It also recommended that firms assess the extent of time pressures on the audit engagements and the firm's success in managing those pressures. Finally, the Panel urged firms to provide guidance and training on actions that engagement partners and other supervisory personnel should consider in managing time pressures.

These concerns have not been ignored in the academic literature. The underlying premise of much academic research has been that DAB is a dysfunctional reaction to the environment (i.e., the control system). These behaviors can, in turn, have both direct and indirect impacts on audit quality. Behaviors that directly affect audit quality include premature signing-off of audit steps without completion of the procedure (Otley and Pierce 1995; Rhode 1978; Alderman and Deitrick 1978), gathering of insufficient evidential materials (Alderman and Deitrick 1982), processing inaccuracy (McDaniel 1990), and the omission of audit steps (Margheim and Pany 1986).

Readers with comments or questions are encouraged to contact the authors via email. 
Underreporting of audit time has also been shown to have an indirect impact on audit quality (Smith 1995; Kelley and Margheim 1990; Lightner et al. 1982). Underreporting time leads to poor personnel decisions, obscures the need for budget revision, and results in unrecognized time pressures on future audits.

Several academic studies have also examined the impact that time pressure has on dysfunctional behavior (Margheim and Pany 1986; Alderman and Deitrick 1978, 1982; Rhode 1978). Kelley and Margheim (1990) examined the moderating effects of the interaction between supervisor leadership style and auditor personality. Otley and Pierce (1995) extend this work by examining the moderating effects of audit managers' leadership style on the behavior of audit seniors. These studies suggest that an optimal supervisor-subordinate fit can help reduce dysfunctional reactions to control systems.

Prior literature has identified environmental factors (e.g., time pressure, supervisory style) that contribute to DAB. However, extant literature has not found that individual differences among auditors significantly affect DAB. In essence, this literature fails to support the claim that predispositions toward DAB may be a function of personal characteristics. In addition, it assumes all auditors will have similar reactions to environmental factors such as time pressure.

The purpose of this study is to investigate factors contributing to individual auditor differences in attitudes toward DAB. Gaining an understanding of such contributory factors parallels the processes outlined in SAS No. 82 that require auditors to view management's attitudes toward misstatements and fraudulent reporting as indicators of actual financial statement fraud (AICPA 1997). Thus, identifying the factors that contribute to an auditor's attitudinal acceptance of DAB is regarded as an important first step in ascertaining the when, why, and how of actual dysfunctional behavior. A theoretical model was developed that relates locus of control, position in the firm, and organizational commitment to auditors' attitudes toward three DABs: premature sign-offs, altering/replacing audit procedures, and underreporting of time in their firms.

Respondents were asked to report their attitudes toward, rather than their actual engagement in, DAB for three reasons. First, auditor acceptance of a behavior by members in the firm is a reflection of the firm's and/or the profession's attitude toward DAB. It is a reflection of the understood norms. A low level of acceptance would suggest that the firm and profession has made it clear to participants that such behaviors are not accepted. A high level of acceptance by firm members is likely to result when others in the organization are accepting of these behaviors. Second, subjects would likely hesitate to admit to engaging in DAB, resulting in either a non-response or a question of response validity (Rest 1979). Third, evidence from Lightner et al. $(1982,1983)$ suggests that personal beliefs impact an auditor's willingness to engage in DAB. Those who are more accepting of a behavior were more likely to engage in the behavior. This attitudinal-based measurement approach has been successfully implemented in the budgetary slack literature (Onsi 1973).

Using a cross-organizational design and a path analysis technique, survey results from 113 auditors support the theoretical model and the hypothesized relationships. Results indicate that locus of control has a direct effect on attitudes toward DAB; internals (externals) were less (more) likely to express a positive attitude toward DAB. Locus of control also affected DAB through its association with organizational commitment. Internals (externals) had higher (lower) levels of organizational commitment and higher (lower) levels of organizational commitment were associated with lower (higher) attitudes toward DAB. In addition, employees at higher (lower) levels of the firm were less (more) likely to accept DAB.

These results contribute to our understanding of the correlates of DAB. In addition to the environmental and control variables examined in previous literature, these findings suggest that individual auditors may differ in their predispositions toward these behaviors. Further research in this area may assist the profession in identifying personality and individual attributes among auditors that will reduce the acceptance of DAB. In addition, improved understanding of the individual characteristics associated with acceptance of DAB can allow firms to target their risk management of DAB to those auditors most likely to have more favorable attitudes toward such behaviors. 
The remainder of this paper is organized into four sections. The first section presents the theoretical development, while the second section discusses the research method including data collection and measurement information. In the third section, empirical results are presented. The final section concludes with a discussion and limitations.

\section{Theoretical Development}

The full theoretical model appears in Figure 1. Each link in the model is labeled with its respective hypothesis and discussed subsequently. The first links to be discussed involve locus of control.

Figure 1

Theoretical Model

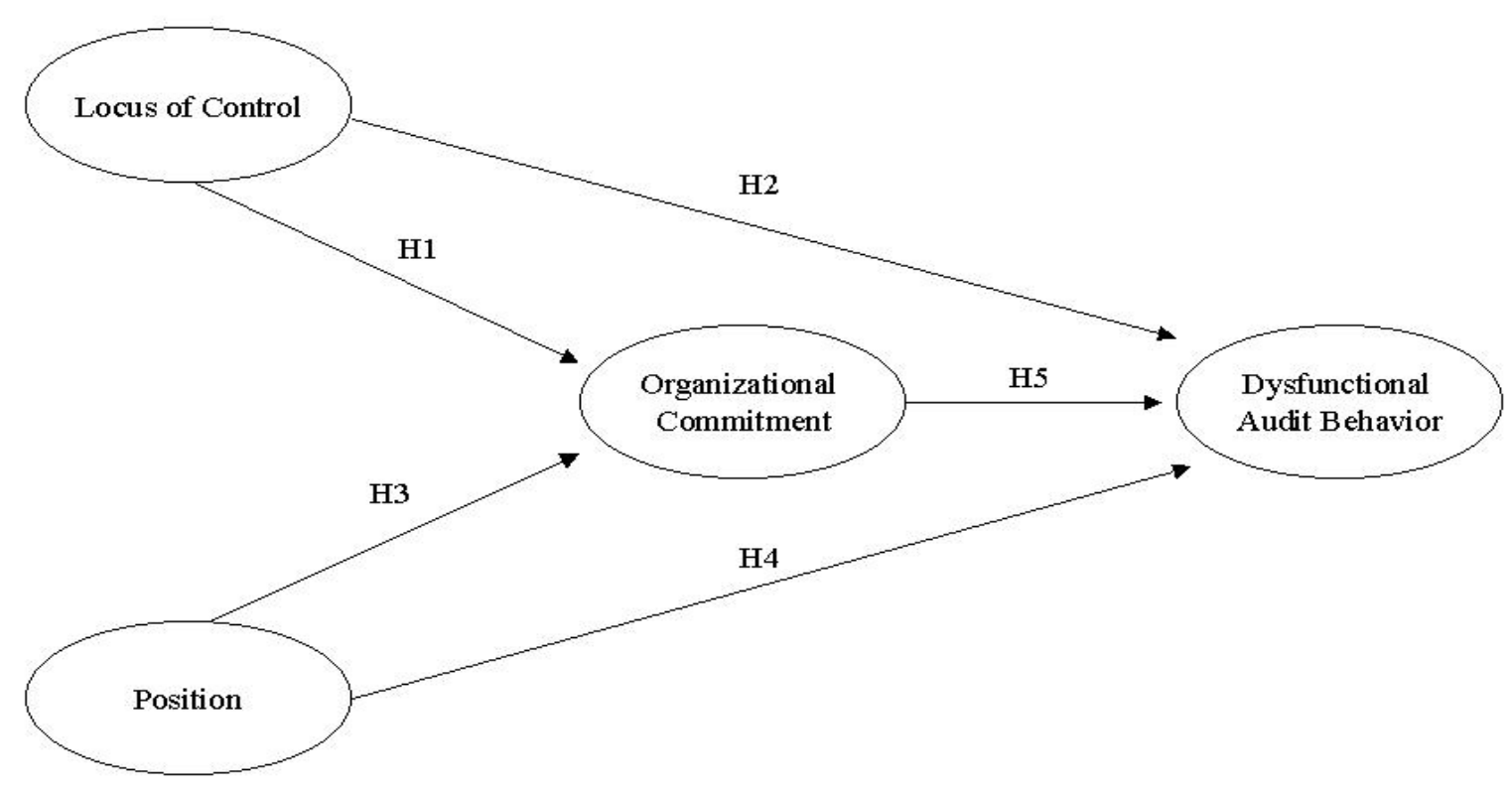

\subsection{Locus of Control and Organizational Commitment}

Locus of control has been used extensively in behavioral research to explain human behavior in organizational settings. Rotter (1966) suggests that individuals develop generalized expectations concerning whether or not success in a given situation will be contingent on their own personal behavior or controlled by external forces. Individuals that tend to associate outcomes with their own efforts, or believe that events are under their own control, are referred to as internals, while externals are those who believe that they cannot control events or outcomes (Spector 1982). Thus, internally and externally directed people can encounter identical situations, yet perceive that their actions will have quite different impacts on their lives.

Locus of control has been found to be an antecedent to organizational commitment (Luthans et al. 1987; Kinicki and Vecchio 1994). Internals perceive that they have more opportunities than do externals. Therefore, 
when internals accept a position with a firm they tend to have a higher commitment to that choice relative to externals. During their tenure with an organization internals will similarly perceive alternatives exist in the job market and by virtue of their remaining with an organization will develop greater organizational commitment. In contrast, externals perceive fewer choices and are less likely to act on these choices. That is, externals may feel they have no choice but to stay with the current company, while internals make an active choice to remain and subsequently increase their commitment to the organization. This leads to the first hypothesis:

H1: There is a negative relationship between external locus of control and organizational commitment.

\subsection{Locus of Control and Attitudes Toward Dysfunctional Audit Behavior}

Studies have shown a strong correlation between locus of control and an individual's willingness to use deception or manipulation (e.g., Gable and Dangello 1994; Comer 1985; Solar and Bruehl 1971). Based on a metaanalytic review of 20 studies examining this relationship, Mudrack (1989) concluded that the use of manipulation, deception, or ingratiation tactics may reflect an attempt on the part of externals to assert some influence over a hostile or stressful environment. In situations where externals are unable to obtain the reinforcements needed for survival, they view manipulation of others as a necessary defense (Solar and Bruehl 1971). Furthermore, this behavior is most likely to manifest itself in situations where the employee perceives a high degree of structure or supervisory control (Gable and Dangello 1994).

In an auditing context, manipulation or deception will manifest itself in the form of DAB. These behaviors are means for the auditor to manipulate the audit process in order to achieve the individual's performance objective. The reduction in audit quality resulting from these actions may be viewed as a necessary sacrifice in order for the individual to survive in the audit environment. It is expected that the higher the individual's external locus of control the more likely they are to accept DAB. This leads to the following hypothesis:

H2: There is a positive relationship between external locus of control and acceptance of dysfunctional audit behavior.

\subsection{Position and Organizational Commitment}

Previous studies have examined the relationship between organizational tenure and organizational commitment based on the premise that individuals become committed to the organization as a result of the accumulated investments they have made in the organization (Becker 1960). Over time, the individual accumulates a greater investment and thus becomes more committed to the organization. In earlier studies, organizational tenure was used as a surrogate measure of the individual's accumulated investments and found to be significantly related to organizational commitment (Alutto et al. 1973; Farrell and Rusbult 1981; Meyer and Allen 1984). Using a metaanalysis of 25 samples based on earlier studies, Mathieu and Zajac (1990) found that organizational tenure was positively correlated with organizational commitment.

In light of the previous research in this area, it is hypothesized that organizational tenure, reflected in the individual's position in the firm, will be positively related to organizational commitment. The following hypothesis results:

H3: There is a positive relationship between position and organizational commitment.

\subsection{Position and Attitudes Toward Dysfunctional Audit Behavior}

Relatively little research has investigated the relationship between organizational tenure and deviant behaviors. However, an individual's position in the firm has been linked to dysfunctional behavior in an audit environment. Kelley and Seiler (1982) found that underreporting of time was more common among senior and staff level auditors. Similarly, Alderman and Deitrick (1982) surveyed audit personnel at all levels of the firm with respect to the occurrence of premature sign-offs during the audit and found significant response differences based on 
position in the firm. The negative impact of $\mathrm{DAB}$ on audit quality coupled with the organizational hierarchy that exists in the accounting profession would suggest that auditors who are employed at higher levels in the firm would be less accepting of DAB. As one progresses up the ranks to partner, auditors would be more likely to recognize the adverse effects of dysfunctional behaviors. They would be expected to have a much higher interest in the quality of services provided by the firm and the resulting firm image. This discussion leads to the following hypothesis:

H4: There is a negative relationship between position and acceptance of dysfunctional audit behavior.

\subsection{Organizational Commitment and Attitudes Toward Dysfunctional Audit Behavior}

Organizational commitment is defined as the acceptance of organizational goals and a willingness to exert effort on behalf of the organization. Research suggests that organizational commitment acts as a measure of the employee's identification with the organization (Hollinger and Clark 1983). Three factors are traditionally used to characterize the commitment construct: a strong belief and acceptance of the organization's values, a willingness to work hard to achieve the organization's objectives, and a desire to maintain membership in the organization (Mowday et al. 1982). Organizational commitment is associated with positive behaviors such as job performance and attendance (Porter et al. 1974). It has also been linked to dysfunctional behaviors such as resistance to change and reluctance to leave due to lack of ability (Aranya and Ferris 1984).

In effect, organizational commitment creates a countervailing force to dysfunctional tendencies. As commitment increases, the organization is viewed as less hostile and manipulation is not necessary to obtain the reinforcements desired. Individuals who possess a strong belief in the organization and who are willing to work hard to achieve organizational objectives should be less likely to resort to unethical and/or dysfunctional tactics to achieve personal goals.

Otley and Pierce (1996) surveyed audit seniors in Ireland and found a significant relationship between organizational commitment and dysfunctional behaviors. Due to differences in organizational and country cultures between Ireland and the United States, the current study attempts to determine whether that result is generalizable to a sample of auditors in the United States.

The pivotal role of organizational commitment may also reflect differences in motivation between individuals with high and low organizational commitment (Nouri and Parker 1996). As Lincoln and Kalleberg (1990) argue, the highly committed employee will expend effort on behalf of the organization even when such effort does not directly contribute to the individual's compensation or career opportunities. Individuals with high organizational commitment want the organization to succeed. If such individuals view certain behaviors as dysfunctional, they may be less accepting of these activities. Individuals with low organizational commitment may be more interested in pursuing self-interest rather than organizational interest. Thus, individuals possessing lower levels of organizational commitment are more likely to view dysfunctional behaviors as acceptable for the purpose of self promotion (e.g., underreporting of time). This discussion leads to the following hypothesis:

H5: There is a negative relationship between organizational commitment and acceptance of dysfunctional audit behavior.

\section{Research Method}

\subsection{Data Collection}

In order to allow for cross-organizational generalizability, data was collected using a survey questionnaire sent to a total of 205 auditors from a cross-section of 10 public accounting firms. Questionnaires were sent out to firms of a wide variety of sizes including Big 5, large international, large national, multi-state regional, and single state. 
A survey instrument package was distributed to each potential respondent via an office partner and returned by the respondents directly to the researchers via mail to ensure confidentiality. Partners were instructed by the researchers to distribute the survey instruments in a random order throughout their offices. Accompanying each questionnaire was a cover letter containing an explanation of the research as well as instructions for completing the survey. A self-addressed, stamped envelope was also included.

Of the 205 surveys distributed, respondents returned a total of 120 usable surveys for an effective response rate of 59 percent. Of the 120 usable responses, there were seven partners, 25 managers, 43 seniors, and 45 staff. Due to the small number of partners in the sample they were excluded from the reported analysis leaving a final sample of 113. The results including the seven partners were qualitatively similar to those reported herein. The average respondent was 29 years old and had 6 years of audit experience. Females represented approximately 48 percent of the returned instruments.

\subsection{Measures}

The variables measured in the questionnaire include locus of control, position, organizational commitment, and attitudes toward dysfunctional audit behavior. While the locus of control and organizational commitment measures were drawn from prior literature, the dysfunctional audit behavior instrument was developed for this study.

Locus of control was measured using the 16-item, Spector (1988) work locus of control scale. The Rotter (1966) measure was not used due to its extremely general scope. Its items cut across several different domains (e.g., education, work, politics, life in general). The Spector (1988) measure has been shown to possess a stronger fit to work-related outcomes (Blau 1993). Using such concepts as job satisfaction, organizational commitment, role stress, and leadership behavior, Spector (1988) found the work locus of control measure to be significantly related to these work outcomes.

Respondents were asked to identify the relationships between reward/outcomes and causes using a sevenpoint Likert-type scale. Higher scores on the work locus of control scale indicate a greater degree of external personality, while lower scores are associated with internal traits. The instrument's reliability and validity have been deemed acceptable in prior research (e.g., Blau 1993; Spector 1988). In the current study, the Cronbach alpha was 0.82 .

For purpose of analysis, a respondent's position within his/her employing firm was categorized as either staff, senior, or manager. A three-point scale anchored with 0 (staff) and 2 (manager) was utilized in the study.

Mowday et al.'s (1979) nine-item short-form instrument was used to measure organizational commitment. The instrument was written in a seven-point Likert-type format ranging from (1) strongly disagree to (7) strongly agree. A response of (7) indicates a high level of organizational commitment. Prior studies report acceptable levels of reliability and validity for the nine-item scale (e.g., Blau 1987; Nouri and Parker 1998). In this study, the Cronbach alpha was 0.92 .

As noted in the introduction, an instrument was developed to measure an auditor's attitudes toward, not actual engagement in, dysfunctional behavior. A 15 -item, three-part dysfunctional audit behavior instrument was designed to capture the required dysfunctional behavior information in an audit environment. Five items relating to each of the three types of dysfunctional audit behavior were included. The items in the instrument were designed to measure how accepting an auditor was to the various forms of dysfunctional behavior. The items were constructed on a seven-point Likert-type scale anchored by (1) strongly disagree and (7) strongly agree. Questions were written so that a response of (7) indicates a positive attitude toward the occurrence of DAB. An overall measure of DAB was obtained by summing the responses on the 15 items.

A principal components, orthogonal rotation factor analysis of the instrument indicated that all five premature sign-off items loaded above 0.5 on a single factor, all five underreporting of time items loaded on a single factor at the 0.5 level, and all five altering/replacement of audit procedure items also loaded on a single factor at the 
0.5 level. Eigenvalues for the premature sign-off, underreporting of time, and altering/replacement of audit procedure factors were $3.638,2.950$, and 2.501 , respectively. The analysis indicated that crossloadings of the questions from the three separate factors were not problematic. Further analysis was done to ascertain the instrument's reliability. The Cronbach alpha for the 15 -item measure was 0.89 , while the reliability alphas for the premature sign-off, underreporting of time, and altering/replacement of audit procedure portions of the survey were $0.82,0.92$, and 0.80 respectively. For hypotheses testing purposes, the entire 15 -item instrument was used.

A copy of each research instrument is available upon request, and descriptive statistics for all measures are reported in Table 1. The descriptive results indicate that auditors tend to be more internally oriented. This is not surprising given that prior research suggests internals are better suited for highly technical or professional positions (Spector, 1982). However, the results show that the degree of internal orientation does vary among auditors. It is expected that auditors with the greatest degree of internal personality will more strongly associate with the behaviors hypothesized for internals, while auditors with weaker internal traits will more likely exhibit behaviors hypothesized for externals.

Table 1

Descriptive Statistics

\begin{tabular}{|l|c|c|c|c|}
\hline \hline Variable & Mean & Std. Deviation & Observed Range & Cronbach Alpha \\
\hline Locus of Control & 43.10 & 9.69 & $20-68$ & 0.82 \\
\hline Position $^{\mathrm{a}}$ & 0.82 & 0.77 & $0-2$ & $-\cdots$ \\
\hline Organizational Commitment & 47.09 & 9.19 & $14-63$ & 0.92 \\
\hline Dysfunctional Behavior & 41.04 & 14.26 & $15-85$ & 0.89 \\
\hline \hline
\end{tabular}

${ }^{\mathrm{a}}$ Of the 113 usable survey instruments returned, 45 were from staff auditors, 43 from seniors, and 25 from managers.

The descriptive results also indicate that, in general, auditors are not accepting of DAB. The mean score of 41.04 reflects a low overall acceptance of $\mathrm{DAB}$ on the part of practicing auditors. This can be considered positive for the profession. It appears that auditors have, in general, incorporated professional standards and an emphasis on audit quality into their personal beliefs. Although on average respondents are not accepting of DAB, the results indicate considerable variation in the level of acceptance among individual auditors. Some auditors are much more accepting of DAB than others.

\subsection{Path Analysis}

Path analysis was used to evaluate the proposed hypotheses. Path analysis, rather than moderated regression analysis (MRA) or ANOVA, was used because the theoretical model presented in the study is viewed as an antecedent nomological framework for dysfunctional audit behavior. Use of path analysis for testing of such frameworks as well as contingency-based hypotheses, like those contained in this study, has been suggested as the statistical method of choice in recent literature (Hartmann and Moers 1999; Shields and Shields 1998).

\section{Empirical Results}

\subsection{Main Analysis}

Table 2 reports the correlation matrix for the variables. Table 3 presents the results of the main analysis and lists each hypothesis and its corresponding path coefficient, each of which were estimated using regression or correlation analysis. Figurative representations of the main results are also displayed in Figure 2. 
Figure 2

Path Analytic Model

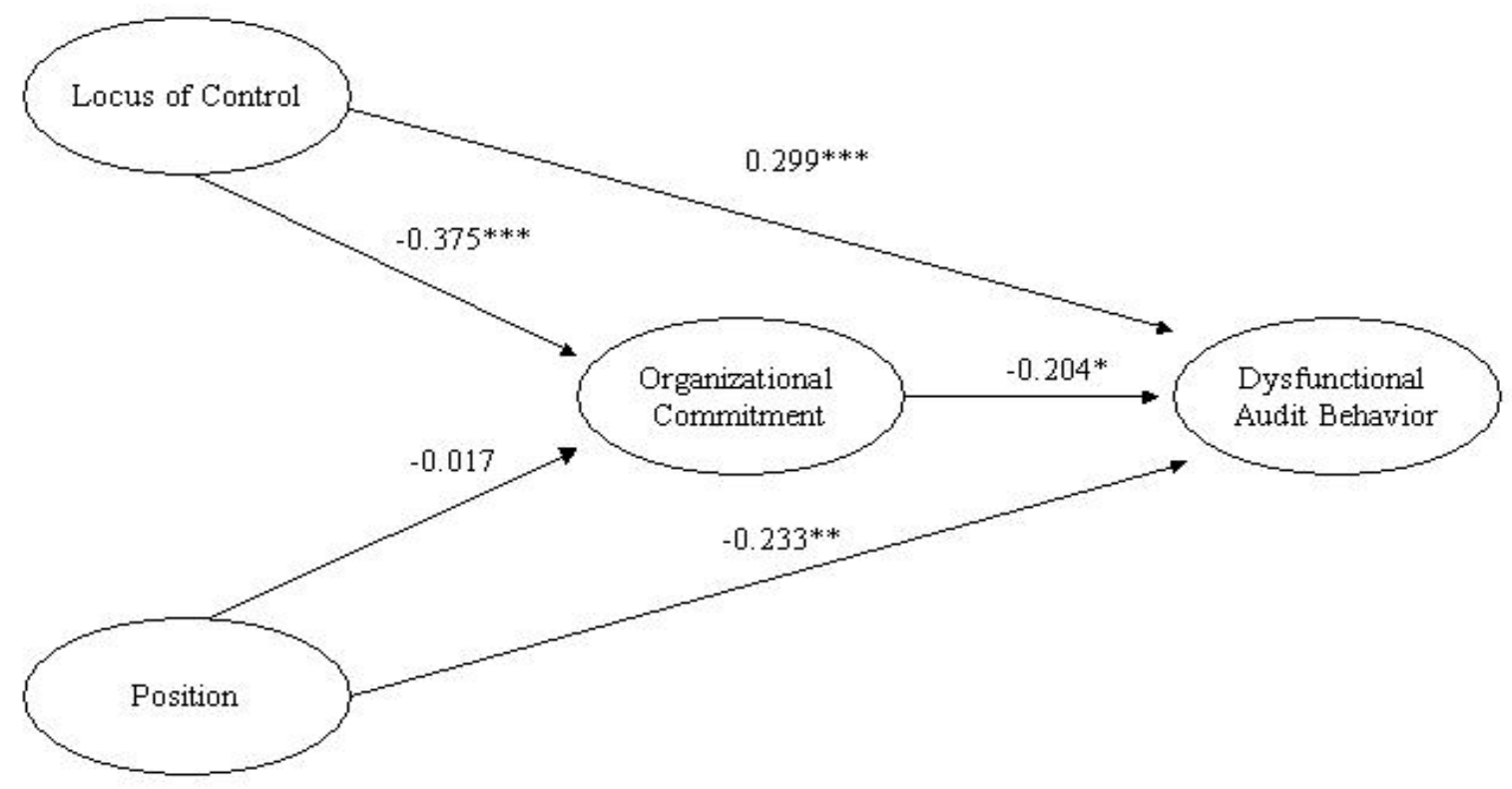

* Sigrific ant at 05 level

** Significant at .01 level

**** Significant at 001 level

Hypothesis 1 predicts that there is a negative relation between external locus of control and organizational commitment. The path coefficient linking locus of control and organizational commitment is -0.375 and is significant at the $\mathrm{p}<.001$ level. Thus, locus of control is negatively associated with organizational commitment implying that internals possess higher levels of commitment than do externals.

Hypothesis 2 predicts that there is a positive relationship between external locus of control and dysfunctional behavior. The corresponding path coefficient is 0.299 and is significant at the $p<.001$ level. This result implies that external (internal) employees are more (less) likely to be accepting of dysfunctional audit behavior.

Hypothesis 3 states that there is a positive relationship between position and organizational commitment. The path coefficient linking these two variables is -0.017 , but it is not significant $(p<.430)$. Thus, this analysis indicates that position does not affect organizational commitment to the extent that prior research and theory suggests it might.

Hypothesis 4 predicts that there is a negative relationship between position and dysfunctional behavior. The path coefficient linking these two variables is -0.233 and is significant at the $p<.004$ level. This result supports hypothesis 4 and suggests that employees at higher levels within the firm are less likely to exhibit acceptance of dysfunctional audit behavior. 
Table 2

Correlation Matrix

\begin{tabular}{|l|c|c|c|c|}
\hline \hline & Locus of Control (1) & Position (2) & $\begin{array}{c}\text { Organizational } \\
\text { Commitment (3) }\end{array}$ & $\begin{array}{c}\text { Dysfunctional } \\
\text { Behavior (4) }\end{array}$ \\
\hline$(1)$ & 1.000 & & & \\
\hline$(2)$ & -0.002 & 1.000 & & 1.000 \\
\hline$(3)$ & $-0.375^{* * *}$ & -0.017 & $-0.312 * * *$ & 1.000 \\
\hline$(4)$ & $0.375^{* * *}$ & $-0.229 * *$ & & \\
\hline \hline
\end{tabular}

$\mathrm{n}=113$

One tailed significance.

$* * \mathrm{p}<.01$

$* * * \mathrm{p}<.001$

Table 3

Path Analysis Results

\begin{tabular}{|c|c|c|c|c|c|}
\hline \hline $\begin{array}{c}\text { Dependent } \\
\text { Variable }\end{array}$ & $\begin{array}{c}\text { Independent } \\
\text { Variable }\end{array}$ & $\begin{array}{c}\text { Associated } \\
\text { Hypothesis }\end{array}$ & $\begin{array}{c}\text { Path } \\
\text { Coefficient }\end{array}$ & t-statistic & p-value \\
\hline OC & LC & H1 & -0.375 & -4.26 & 0.001 \\
\hline OC & P & H3 & -0.017 & -0.18 & 0.430 \\
\hline DB & LC & H2 & 0.299 & 3.30 & 0.001 \\
\hline & P & H4 & -0.233 & -2.77 & 0.004 \\
\hline & OC & H5 & -0.204 & -2.24 & 0.013 \\
\hline \hline
\end{tabular}

$\mathrm{n}=113$

LC $=$ Locus of Control, $\mathrm{P}=$ Position, $\mathrm{OC}=$ Organizational Commitment, $\mathrm{DB}=$ Dysfunctional Behavior.

Hypothesis 5 predicts that there is a negative relationship between organizational commitment and dysfunctional behavior. The path coefficient for this theoretical link is -0.204 and is significant at the $p<.013$ level. Thus, employees possessing higher levels of organizational commitment are less likely to be accepting of dysfunctional audit behavior.

\subsection{Additional Analysis: Locus of Control Main Effects}

The overall, significant effect of locus of control in the theoretical model motivated an additional analysis of the main effects of locus of control on organizational commitment and DAB. For this purpose, the sample was split at the median locus of control value. Those scoring above (below) the median were classified as externals (internals). This resulted in 56 internals and 57 externals. Table 4 reports that externals reported a higher acceptance of DAB $(p<.001)$ and possessed lower levels of organizational commitment $(p<.001)$ than did internals. These results reinforce those from the main analysis and point to an important role that locus of control may play in improving audit quality and increasing organizational commitment. 
Table 4

Locus of Control Mean Analysis

\begin{tabular}{|l|c|c|c|}
\hline \hline & $\begin{array}{c}\text { Internals } \mathrm{n}=56 \\
\text { Mean } \\
\text { (Std. Dev.) }\end{array}$ & $\begin{array}{c}\text { Externals } \mathrm{n}=57 \\
\text { Mean } \\
\text { (Std. Dev.) }\end{array}$ & $\begin{array}{c}\text { t statistic } \\
(\mathrm{p} \text { value) }\end{array}$ \\
\hline Dysfunctional Audit Behavior & $\begin{array}{c}36.20 \\
(11.99)\end{array}$ & $\begin{array}{c}45.79 \\
(14.80)\end{array}$ & $\begin{array}{c}-3.79 \\
(.001)\end{array}$ \\
\hline Organizational Commitment & $\begin{array}{c}49.61 \\
(8.45)\end{array}$ & $\begin{array}{c}44.61 \\
(9.29)\end{array}$ & $\begin{array}{c}(.001) \\
\end{array}$ \\
\hline \hline
\end{tabular}

\section{Discussion}

The purpose of this study was to empirically test a theoretical model of antecedents to dysfunctional behavior. This model suggests that locus of control, organizational commitment, and position in the firm all influence auditors' attitudes toward, and acceptance of, DAB. These results have several important implications for the auditing profession.

Auditors with the strongest internal locus of control traits were less likely to accept dysfunctional behavior. In addition, they had significantly higher levels of organizational commitment and increased organizational commitment was associated with lower levels of DAB. As a result, this study identifies organizational commitment as an important influence on DAB. Since internals reported higher levels of organizational commitment, focusing recruiting and hiring efforts on internals is one approach to managing this construct. Additional research is needed to identify additional ways to increase the organizational commitment of auditors after they are hired. The organizational theory and behavior literature on organizational commitment will likely be a helpful guide for this research.

In addition, the results indicate that acceptance of $\mathrm{DAB}$ was greatest at the staff level and then decreased with position up to manager. The underlying reasons for this relationship between position and attitudes toward $\mathrm{DAB}$ are unclear, but several plausible explanations can be offered. Attrition may explain this finding as those who are more accepting of $\mathrm{DAB}$ may leave the firm before advancing to higher levels. Training and indoctrination into the cultural norms of the organization and auditing profession may also explain this finding. As individuals advance to higher levels and take on supervisory responsibilities, they may have a better understanding of what constitutes $\mathrm{DAB}$ and why it is harmful to the firm and profession. The important management implication is to recognize that $\mathrm{DAB}$ varies among firm positions and to begin searching for the additional reasons for this variance. Once the underlying reasons are identified, then firms may be able to implement changes (e.g., better and more training about $\mathrm{DAB}$, changes in the reward system) that could reduce DAB at all levels of the firm. This study suggests that efforts to control and reduce dysfunctional behaviors might best be targeted toward lower-level employees, especially those with higher (i.e., external) scores on the locus of control scale.

Results of this study also suggest that locus of control may play a significant role in auditor behavior. Although auditors tend to be internally-oriented, findings indicate that the strength of these internal traits significantly influences organizational commitment. With prior research asserting that organizational commitment is related to a host of other employee characteristics such as performance and longevity (Mathieu and Zajac 1990), it is possible that auditors with weaker internal personalities are more likely to feel unable to achieve their performance objectives. This is especially true in a public accounting environment where the meeting of time deadlines and budget estimates are an important part of the evaluation process. In this situation, those employees not possessing internal characteristics are more likely to view DAB as an acceptable means of influencing the environment. The challenge for the auditing profession is to use this information to address the negative consequences associated with a weak internal personality. 
These findings also provide strong support for the recommendations provided by the Panel on Audit Effectiveness (Public Oversight Board, 2000). Specifically, the Panel recommends that firms emphasize the importance of performing high-quality work and that this becomes the highest priority in performance evaluations, compensation, promotion, and retention decisions. The Panel also recommends that all personnel understand that quality work, not meeting time deadlines and budget estimates, is the ultimate priority. The implementation of these principles is likely to provide staff auditors with the perception of greater control over their environment.

\section{Limitations and Implications for Future Research}

When assessing the implications of this study, it is necessary to understand that the findings are subject to a number of limitations. First, this study measured attitudes toward, not the actual occurrence of, dysfunctional behavior. There is some research to suggest acceptance of, and favorable attitudes toward, certain behavior is correlated with engagement in that behavior (Lightner et al. 1982, 1983). However, the underlying degree of correlation in this study between attitudes and actual behavior is unknown. Second, survey studies are subject to both lack of control limitations and potential bias associated with self-reporting. Third, problems of omitted and uncontrolled intervening or moderating variables may exist. Fourth, this study focused only on the auditing environment. Future research is needed to determine whether the variables examined in this study also lead to dysfunctional behaviors in other accounting settings. Lastly, path analysis relies on correlation, which does not prove causality. Theory driven linkages in conjunction with empirical support suggests causal linkages as specified in Figure 1. While alternative methodologies, such as controlled experiments, could provide stronger evidence of causality, the manipulation of personal characteristics, such as organizational commitment and locus of control, is problematic.

\section{References}

1. Alderman, C. W. and J. W. Deitrick, "Survey of the Impact of Time Budgets on Audit Performance," Proceedings, American Accounting Association, Southeastern Regional Meeting, Sarasota, FL, pp. 456474, 1978.

2. "Auditor's Perceptions of Time Budget Pressures and Premature Sign-Offs: A Replication and Extension," Auditing: A Journal of Practice \& Theory, Vol. 1, pp.54-68, 1982.

3. Alutto, J. A., L. G. Hrebiniak and R. C. Alonso, "On Operationalizing the Concept of Commitment," Social Forces, Vol. 51, pp. 448-454, 1973.

4. American Institute of Certified Public Accountants, Consideration of Fraud in a Financial Statement Audit, Statement on Auditing Standards No. 82, New York, NY, AICPA, 1997.

5. Aranya, N. and K. R. Ferris, "An Examination of Accountants' Organizational-Professional Conflict," The Accounting Review, January, pp. 1-15, 1984.

6. Asher, R., Causal Modeling, London, Sage, 1983.

7. Becker, H. S., "Notes on the Concept of Commitment," American Journal of Sociology, Vol. 66, pp. 32-40, 1960.

8. Blau, G., "Using a Person-Environment Fit Model to Predict Job Involvement and Organizational Commitment," Journal of Vocational Behavior, Vol. 30, pp. 240-257, 1987.

9. _ "Testing the Relationship of Locus of Control to Different Performance Dimensions," Journal of Occupational and Organizational Psychology, Vol. 66, pp. 125-138, 1993.

10. Comer, J. M., "Machiavellianism and Inner vs Outer Directedness: A Study of Sales Managers," Psychological Reports, Vol. 56, pp. 81-82, 1985.

11. Farrel, D. and C. E. Rusbult, "Exchange Variables as Predictors of Job Satisfaction, Job Commitment, and Turnover: The Import of Rewards, Costs, Alternatives, and Investments," Organizational Behavior and Human Performance, Vols. 27-28, pp. 78-95, 1981.

12. Gable, M., and F. Dangello, "Locus of Control, Machiavellianism, and Managerial Job Performance," The Journal of Psychology, Vol. 128, pp. 599-608, 1994.

13. Hartmann, F., and F. Moers, "Testing Contingency Hypotheses in Budgetary Research: An Evaluation of the Use of Moderated Regression Analysis," Accounting, Organizations and Society, Vol. 24, pp. 291-315, 1999. 
14. Hollinger, R., and J. Clark, Theft byEemployees, Lexington, MA, Lexington Books, 1983.

15. Kelley, T. and L. Margheim, "The Impact of Time Budget Pressure, Personality, and Leadership Variables on Dysfunctional Auditor Behavior," Auditing: A Journal of Practice \& Theory, Vol. 9, pp. 21-42, 1990.

16. Kelley, T. and R. Seiler, "Auditor Stress and Time Budgets," CPA Journal, Vol. 52, pp. 24-32, 1982.

17. Kinicki, A. J. and R. P. Vecchio, "Influences on the Quality of Supervisor-Subordinate Relations: The Role of Time-Pressure, Organizational Commitment, and Locus Of Control," Journal of Organizational Behavior, Vol. 15, pp. 75-82, 1994.

18. Lightner, S. M., S. J. Adams and K. M. Lightner, "The Influence of Situational, Ethical, and Expectancy Theory Variables on Accountants' Underreporting Behavior," Auditing: A Journal of Practice \& Theory, Vol. 2, pp. 1-12, 1982.

19. Lightner, S. M., J. J. Leisenring and A. J. Winters, "Underreporting Chargeable Time: Its Effects on Client Billing, Future Budget Preparation and Staff Evaluation and Scheduling," Journal of Accountancy, Vol. 156, pp. 52-57, 1983.

20. Lincoln, J. and A. Kalleberg, Culture, Control, and Commitment, Cambridge, Cambridge University Press, 1990.

21. Luthans, F., D. Baack and L. Taylor, "Organizational Commitment: Analysis of Antecedents," Human Relations, Vol. 40, No. 4, pp. 219-36, 1987.

22. Margheim, L. and K. Pany, "Quality Control, Premature Signoff, and Underreporting of Time: Some Empirical Findings," Auditing: A Journal of Practice \& Theory, Vol. 5, pp. 50-63, 1986.

23. Mathieu, J. E., and D. M. Zajac, "A Review and Meta-Analysis of the Antecedents, Correlates, and Consequences of Organizational Commitment," Psychological Bulletin, Vol. 108, pp. 171-194, 1990.

24. McDaniel, L. S., "The Effects of Time Pressure and Audit Program Structure on Audit Performance," Journal of Accounting Research, Vol. 28, pp. 267-285, 1990.

25. Meyer, J. P. and N. J. Allen, "Testing the 'Side-Bet Theory' of Organizational Commitment: Some Methodological Considerations,” Journal of Applied Psychology, Vol. 69, pp. 372-378, 1984.

26. Mowday, R. T., L. W. Porter and R. M. Steers, Employee-Organizational Linkages, New York, Academic Press, 1982.

27. Mowday, R. T., R. M. Steers and L. W. Porter, "The Measurement of Organizational Commitment," Journal of Vocational Behavior, Vol. 14, pp. 224-227, 1979.

28. Mudrack, P. E., "Machiavellianism and Locus of Control: A Meta-Analytic Review," The Journal of Social Psychology, Vol. 130, pp. 125-126, 1989.

29. Nouri, H. and R. J. Parker, "The Effect of Organizational Commitment on the Relation Between Budgetary Participation and Budgetary Slack," Behavioral Research in Accounting, Vol. 8, pp. 74-90, 1996.

30. Nouri, H., and R. J. Parker, "The Relationship Between Budget Participation and Job Performance: The Roles of Budget Adequacy and Organizational Commitment," Accounting, Organizations, and Society, Vol. 23, pp. 467-483, 1998.

31. Onsi, M., "Factor Analysis of Behavioral Variables Affecting Budgetary Slack," The Accounting Review, Vol. 48, pp. 535-548, 1973.

32. Otley, D. and B. Pierce, "The Control Problem in Public Accounting Firms: An Empirical Study of the Impact of Leadership Style," Accounting, Organizations and Society, Vol. 20, pp. 405-420, 1995.

33. _ "The Operation of Control Systems in Large Audit Firms," Auditing: A Journal of Practice \& Theory, Vol. 15, No. 2, pp. 65-84, 1996.

34. Porter, L. W., R. M. Steers, R. T. Mowday and P. V. Boulian, "Organizational Commitment, Job Satisfaction, and Turnover Among Psychiatric Technicians," Journal of Applied Psychology, Vol. 59, No. 5, pp. 603-9, 1974.

35. Public Oversight Board, The Panel on Audit Effectiveness Report and Recommendations, Stamford, CT, Public Oversight Board, 2000.

36. Reichers, A. E., "Conflict and Organizational Commitments,” Journal of Applied Psychology, Vol. 71, pp. 508-514, 1986.

37. Rest, J., Development in Judging Moral Issues, Minneapolis, University of Minnesota Press, 1979.

38. Rhode, J. G., "Survey on the Influence of Selected Aspects of the Auditor's Work Environment on Professional Performance of Certified Public Accountants," Issued as the Independent Auditor's Work Environment: A Survey, New York, NY, American Institute of Certified Public Accountants, 1978. 
39. Rotter, J. B., "Generalized Expectancies for Internal versus External Control of Reinforcement," Psychological Monographs, Vol. 80, whole no. 609, 1966.

40. Shields, J. F. and M. D. Shields, “Antecedents of Participative Budgeting," Accounting, Organizations and Society, Vol. 23, pp. 49-76, 1998.

41. Smith, R., “Underreporting Time: An Analysis of Current Tax Practice," Journal of Applied Business Research, Vol. 11, pp. 39-45, 1995.

42. Solar, D. and D. Bruehl, "Machiavellianisn and Locus of Control: Two Conceptions of Interpersonal Power," Psychological Reports, Vol. 29, pp. 1079-1082, 1971.

43. Spector, P. E., "Behavior in Organizations as a Function of Employee's Locus of Control," Psychological Bulletin, Vol. 91, pp. 482-497, 1982.

44. _ "Development of the Work Locus of Control Scale," Journal of Occupational Psychology, Vol. 61, pp. 335-340, 1988.

Notes 
Notes 